\title{
Neurological manifestations of organophosphorous insecticide poisoning
}

\author{
R. S. WADIA, C. SADAGOPAN, R. B. AMIN, AND H. V. SARDESAI \\ From the Neurology Clinic, B.J. Medical College and Sassoon General Hospitals, Poona-I, India
}

SYNOPSIS Neurological findings are described in 200 consecutive cases of suicidal ingestion of organophosphorous insecticides. Miosis is almost universal. We found impairment of consciousness in $10 \%$, fasciculations in $27 \%$, convulsions in $1 \%$, toxic delirium in $50 \%$, and paralysis in $26 \%$. Toxic delirium was attributed to treatment with atropine. Paralytic signs were divided into type 1 signs (present on admission) and type 2 signs (appearing later while on atropine treatment). Type 1 signs, chiefly impaired consciousness and bilateral pyramidal tract signs, respond to atropine. The most common type 2 signs are proximal limb weakness, areflexia, and cranial nerve palsies. EMG studies during type 2 paralysis show a myasthenic response in some cases. Of 36 cases with type 2 signs 15 died from respiratory paralysis after a variable period of artificial respiration. Twenty-one recovered and no residual neurological deficit has been noted. Atropine did not influence type 2 paralysis. It is claimed that type 2 signs differ significantly from those described before as 'delayed neurotoxicity' and may represent an alternative mode of human toxicity with organophosphorous compounds.

Poisoning with organophosphorous insecticides (usually Diazinon) has become very common in India. In 1969 we estimated that there had been 1,500 such cases admitted to the Sassoon General Hospitals in Poona in the last three years, with 140 deaths (Wadia and Pherwani, 1969). Since then there appears to have been no decrease in incidence.

Organophosphorous compounds produce clinical manifestations by depression of the enzyme cholinesterase (Nachmansohn and Feld, 1947) resulting in the accumulation of acetylcholine at various receptors. This has three types of effects: (1) muscarinic, (2) nicotinic, and (3) central effects (Grob and Harvey, 1953; Holmstedt, 1959). Muscarinic effects are due to actions on bronchi, salivary, lacrimal, sweat glands, etc., and give rise to pulmonary oedema, sweating, and bradycardia. Nicotonic effects are motor and sympathetic and lead to fasciculations, muscular weakness, and tachycardia. The central effects lead to giddiness, anxiety, emotional lability, ataxia, confusion, and apathy (Namba et al., 1971).
It is surprising, therefore, that with such an array of possible neurological manifestations clinicians have paid scant attention to neurological deficits in poisoning due to organophosphorous insecticides, with the exception of triorthocresyl phosphate.

\section{METHODS}

This is a study of 200 consecutive cases of organophosphorous poisoning admitted to one unit of the Sassoon General Hospitals, from January 1971 to February 1973. At all times we have been on the alert for neurological lesions; these are frequently subtle and often missed. With time, we have elaborated a set proforma of tests to be carried out and the results have been serially checked. Correlation has been attempted with the amount of poison ingested, the time of admission of the patient to hospital after ingestion of poison, and the level of serum and erythrocyte (RBC) cholinesterase; electromyography (EMG), electroencephalography (EEG), muscle biopsy, and necropsy studies have also been performed. This paper reports on the incidence, clinical nature, and 
course of the neurological deficits. The electrophysiological and histopathological studies will be reported separately.

The treatment in all these cases was atropine in varying doses depending on the clinical picture. Pyridine 2-aldoxime methiodide (P2AM) was available only rarely and usually in inadequate amounts. The drug had not yet entered the Indian market.

\section{RESULTS}

We have noted six different forms of neurological syndromes associated with Diazinon poisoning (Table 1). Obviously one case may

TABLE 1

NEUROLOGICAL FINDINGS ASSOCIATED WITH ORGANOPHOSPHOROUS INSECTICIDE POISONING

\begin{tabular}{lcc}
\hline Neurological signs & $\begin{array}{c}\text { Patients } \\
\text { (no.) }\end{array}$ & $\begin{array}{c}\text { Incidence } \\
(\%)\end{array}$ \\
\hline A. Due to insecticide & & \\
Miosis & 190 & 95 \\
Impaired consciousness & 20 & 10 \\
Fasciculations & 54 & 27 \\
Convulsions & 2 & 1 \\
Paralytic signs & 52 & 26 \\
$\begin{array}{l}\text { B. Due to treatment (atropine) } \\
\text { Toxic delirium }\end{array}$ & 100 & \\
\hline
\end{tabular}

belong to more than one category and a number of poisoning cases may not show any of these deficits. Constricted pupils are one of the hall marks of Diazinon poisoning and were seen in all but the mildest cases.

The paralytic cases are of two types. The type 1 case shows paralytic signs on admission. These signs have appeared in the absence of atropine treatment and some of them at least respond to atropine. This group is divided into type 1a when the signs are seen in patients admitted within four hours of ingestion of poison and type $1 \mathrm{~b}$ when patients are admitted more than four hours after ingestion of the poison. In type 2 cases the paralytic signs appear about 24 hours after admission and after atropine has already been given in large doses, usually $30 \mathrm{mg}$ or more. These signs are unlikely to respond to further atropine and often do not respond to P2AM. It is, of course, possible for a patient to be a type 1 case, to recover with atropine, and later develop type 2 paralysis. There were 11 type $1 \mathrm{a}, 10$ type $\mathbb{D}$ $1 \mathrm{~b}$, and 36 type 2 cases. Five cases of type $1 \mathrm{a}$ went later into type 2 paralysis and are included in both groups.

Unconsciousness was always a type 1 sign and SOD $^{+}$ fasciculation was a type 1 sign in the majority. $\frac{\rho}{}$ Chronic paralysis as described by others (Davignon et al., 1965) with other varieties of. organophosphorous insecticides was not seen in $\overrightarrow{\bar{c}}$ this series and has not been described in Diazinon poisoning (Namba et al., 1971). Toxic delirium was the most common finding in this series but occurred due to atropine rather than in spite of it. $\stackrel{\widehat{D}}{\mathrm{D}}$

UNCONSCIOUSNESS OR IMPAIRED CONSCIOUSNESS Consciousness was impaired on admission in 20 cases. It rarely appeared as a late manifestation, $\vec{\omega}$ for cases in extremis with respiratory paralysis were usually alert enough to obey orders. This could not be correlated with the amount of $\omega$ poison consumed (Karnik et al., 1970). This varied from 8 to $15 \mathrm{ml}$ of a $20 \%$ solution in

TABLE 2

IMPAIRMENT OF CONSCIOUSNESS: COURSE

$\begin{array}{cccc}\text { Group and subgroup } & \begin{array}{c}\text { Late } \\ \text { neurological } \\ \text { deficit }\end{array} & \begin{array}{c}\text { Pulmonary } \\ \text { oedema }\end{array} & \begin{array}{c}\text { Late } \\ \text { neurological } \\ \text { deficit }\end{array}\end{array}$

Group A (6)

Flaccid (5)

Hyper-reflexia (1)

$\mathbf{0}$

5
0

0

Group B (5)

Flaccid (2)

Hyper-reflexia (3)

0

0

Flaccid (5)

Hyper-reflexia (4)

* Numbers of cases in parentheses.

but two cases. (The drug is marketed as an insecti-윽 cide in $15 \mathrm{ml}$ bottles and this is the usual dose ingested.) Thirteen of these 20 cases came to hospital within three hours of consumption of $N$ the poison. Table 2 shows the associated clinical $N$ features and course of these 20 cases.

Cases of unconsciousness are divided into $\omega$ three groups, (A) with cyanosis and gross pul- 
monary oedema, (B) with obvious pulmonary oedema but no cyanosis, and (C) where pulmonary oedema was mild or absent. The last group is perhaps the most interesting as it shows the direct effect of the drug uninfluenced by hypoxia. This last group was for some reason more prone to develop late neurological deficit and consciousness tended to clear less rapidly with atropine. On the whole, loss of consciousness, like pulmonary oedema, responded well to atropine. The combination of unconsciousness, cyanosis, and flaccidity, however, had a grave prognosis.

FASCICULATIONS Fifty-four cases showed fasciculation during the hospital stay. In 40 cases it was present on admission, in 14 cases it appeared later, and in 12 of the latter the fasciculations were associated with neurological deficits (type 2). Fasciculation could not be correlated with the amount of poison consumed $(8-30 \mathrm{ml})$ or the time of admission ( 30 minutes-67 hours). Table 3 shows the outcome of these cases and the relation of fasciculations to neurological deficit.

TABLE 3

FASCICULATIONS

\begin{tabular}{lcc}
\hline & $\begin{array}{c}\text { Present on } \\
\text { admission }\end{array}$ & $\begin{array}{c}\text { Appeared } \\
\text { later }\end{array}$ \\
\hline Cases (no.) & 40 & 14 \\
$\begin{array}{l}\text { Death with pulmonary oedema } \\
\text { Type 1 deficit only (no.) }\end{array}$ & 1 & 0 \\
$\begin{array}{l}\text { Developed neurological deficit later } \\
\text { (type 2) }\end{array}$ & 5 & 0 \\
$\begin{array}{l}\text { Had initial deficit and again later } \\
\text { (type 1 } \rightarrow \text { type 2) }\end{array}$ & 3 & 10 \\
No neurological deficit & 6 & 2 \\
\hline
\end{tabular}

CONVULSIONS Convulsions are one of the commonest manifestations of organophosphorous poisoning in animals (Holmstedt, 1959) but were seen only twice in this series. In case 85 they occurred once just before the patient was put on intermittent positive pressure respiration for respiratory paralysis, and once while the patient was on the respirator. In case 84 , they occurred nine hours after admission when there was no apparent anoxia or any electrolyte abnormality. This was soon followed by florid paralysis and the patient died on the fifth hospital day with respiratory paralysis. We have seen one other patient who developed temporal lobe epilepsy three months after hospitalization for severe poisoning with unconsciousness.

PARALYTIC SIGNS Paralyses of various types were noted in 52 cases. In 16 cases they were present on admission (type 1). In 31 cases they appeared later (type 2) and in five of the cases they were present at admission, disappeared, and returned later (type 1 and 2). Table 4 lists these signs and divides them into type $1 \mathrm{a}, 1 \mathrm{~b}$, and type 2 as previously described.

TABLE 4

CLASSIFICATION OF PARALYTIC SIGNS

\begin{tabular}{lrrr}
\hline \multirow{2}{*}{ Neurological signs } & \multicolumn{2}{c}{ Type 1} & \multirow{2}{*}{ Type 2 } \\
\cline { 2 - 3 } & $a$ & $b$ & \\
\cline { 2 - 3 } Total cases & 11 & 10 & 36 \\
Inability to lift neck off bed & 1 & 6 & 24 \\
Inability to sit up & 3 & 7 & 31 \\
Paralysis of eye muscles & 0 & 3 & 18 \\
Slow eye movements & 0 & 2 & 10 \\
Facial paralysis & 3 & 9 & 26 \\
Respiratory paralysis & 0 & 3 & 14 \\
Swallowing problems & 0 & 2 & 8 \\
Limb weakness, proximal > distal & 0 & 3 & 24 \\
Bilateral pyramidal tract signs & 8 & 3 & 0 \\
Areflexia & 0 & 6 & 18 \\
Death & 0 & 2 & 15 \\
& & & \\
\hline
\end{tabular}

The most striking difference in the two groups is the presence of bilateral pyramidal tract signs exclusively in type 1 and slow eye movements exclusively in type 2 except in two patients of type $1 \mathrm{~b}$ who were admitted very late. Gross limb weakness usually affecting proximal muscles more than distal and lower limbs more than upper was commonly seen in type 2 cases, never in type $1 \mathrm{a}$ and occasionally in type $1 \mathrm{~b}$. In the most serious cases power was reduced to grade 2 in the hip flexors. In several others the patient could lift the lower limb against gravity for only a fraction of time. In some the limb could be held up against gravity for a while and a gross tremor was noted in this position. Its significance was not clear and was ascribed to weakness. In all cases the lower limb weakness was much more marked than in the upper limbs. All cases of 
TABLE 5

TIME COURSE OF NEUROLOGICAL DEFICIT

\begin{tabular}{|c|c|c|c|c|c|c|c|c|c|}
\hline \multirow{2}{*}{\multicolumn{2}{|c|}{ Deficit }} & \multirow{2}{*}{$\begin{array}{l}\text { Cases } \\
\text { total } \\
\text { (no.) }\end{array}$} & \multicolumn{7}{|c|}{ Period to normalization $(\mathrm{hr})$} \\
\hline & & & $0-12$ & $12-24$ & $24-35$ & $36-48$ & $48-72$ & $72-96$ & $96+$ \\
\hline \multirow{3}{*}{\multicolumn{2}{|c|}{$\begin{array}{l}\text { A. Patients who survived } \\
\text { Inability to lift neck } \\
\text { Inability to sit up } \\
\text { Eye signs } \\
\text { Facial palsy } \\
\text { IX and X cranial nerve palsy } \\
\text { Limb weakness }\end{array}$}} & $\begin{array}{r}10 \\
16 \\
8 \\
12 \\
2 \\
7\end{array}$ & $\begin{array}{l}3 \\
0 \\
0 \\
4 \\
0 \\
0\end{array}$ & $\begin{array}{l}5 \\
6 \\
3 \\
3 \\
1 \\
3\end{array}$ & $\begin{array}{l}0 \\
2 \\
3 \\
1 \\
0 \\
0\end{array}$ & $\begin{array}{l}0 \\
3 \\
1 \\
2 \\
0 \\
2\end{array}$ & $\begin{array}{l}2 \\
5 \\
1 \\
1 \\
0 \\
1\end{array}$ & $\begin{array}{l}\mathbf{0} \\
\mathbf{0} \\
\mathbf{0} \\
\mathbf{1} \\
\mathbf{1} \\
\mathbf{1}\end{array}$ & $\begin{array}{l}\mathbf{0} \\
\mathbf{0} \\
\mathbf{0} \\
\mathbf{0} \\
\mathbf{0} \\
\mathbf{0}\end{array}$ \\
\hline & & & \multicolumn{7}{|c|}{ Time of death from onset of paralysis } \\
\hline & & 15 & 2 & 2 & 1 & 2 & 2 & 3 & 3 \\
\hline
\end{tabular}

facial paralysis were of the lower motor neurone type and usually bilateral, but in three cases it was unilateral. The ocular paralysis consisted usually of bilateral 6th and occasionally of 3rd nerve paralysis. In two cases there was total external ophthalmoplegia. In five cases we noted paralysis of lateral conjugate movements; four of these were type 2 and one type $1 \mathrm{~b}$. In two cases with slow eye movement, the effects of cold and hot caloric stimulation were examined. In one normal nystagmus appeared, in the other nystagmus was not seen and the eyes merely deviated to one side. Of type 2 cases $50 \%$ had total areflexia and all had some depression of jerks. The type $1 \mathrm{~b}$ group also showed areflexia in about a half of all cases. Ataxia greater than could be expected from weakness was never noted and sensory loss was found in only one case and ascribed to a pressure palsy due to physical restraint when delirious. The type 1 cases responded well to atropine alone and death was uncommon. The type 2 signs appeared after heavy atropine treatment and did not respond to further atropine. The mortality of these cases was high $-41 \cdot 6 \%$.

COURSE OF PARALYTIC SIGNS The Figure gives the time of onset of type 2 signs after admission and the dose of atropine received up to that time. The time of onset varied from nine hours to 85 hours and the patients who died appeared similar to the ones who survived. Only two cases had received less than $6.0 \mathrm{mg}$ atropine at the time of paralysis. In both, the initial diagnosis was in

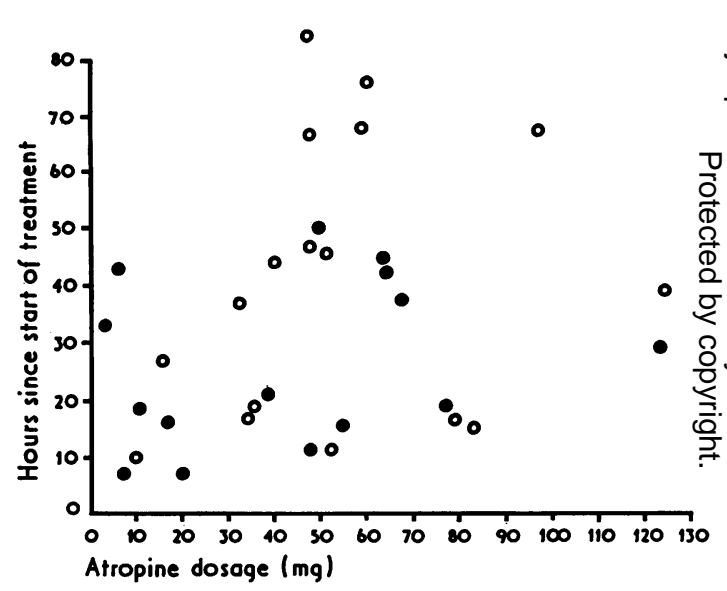

FIGURE Time of onset of type 2 signs after admission and atropine dosage. $\bigcirc=$ Survivors. $O=$ Fatal cases .

doubt and so the dose given was very conservative.

Table 5 shows the duration of type 2 signs.

Fifteen of 36 cases died. The others made a complete recovery. Table 5 shows the duration of $\dot{\delta}$ the signs in those who recovered. They generally lasted only 72 hours with an inability to sit up from 윽 lying being usually the most persistent. In those $D$ who died all signs generally persisted and the time of death in these 15 cases is also shown in $N$ Table 5. Neither in the time of onset nor in the duration of the disease do the fatal cases appear to differ from the non-fatal ones. Those who died after 72 hours of disease were usually main- 
tained on a respirator for several hours before death. The longest delayed death was some 130 hours after paralysis. The signs seen in the fatal and non-fatal cases differed only in degree, respiratory paralysis being the only sign seen in the fatal cases which was absent in the survivors. In this series only one patient who developed respiratory paralysis survived.

TOXIC DELIRIUM The commonest neurological manifestation in these cases was toxic delirium, which we attributed to atropine overdosage. The chief manifestations were garrulousness, tactile and visual hallucinations, failure to recognize persons, and restlessness.

Toxic delirium was usually associated with tachycardia and hot flushed skin and was an indication to omit atropine at least temporarily. The lowest cumulative dose at which it was seen was $5.4 \mathrm{mg}$ and the highest was $165.0 \mathrm{mg}$. This last patient was paranoid and hallucinated and in this state sustained a fracture of the wrist. Table 6 lists the time course and results of the cases with toxic delirium.

CORRELATION OF SIGNS WITH OTHER PARAMETERS We have previously shown that the severity of Diazinon poisoning correlates poorly with the amount of poison ingested (Karnik et al., 1970). This was also noted for neurological deficits. The correlation with time of admission is shown in Table 6. Even cases admitted early were liable

TABLE 6

COURSE OF TOXIC DELIRIUM

\begin{tabular}{|c|c|c|c|c|c|}
\hline \multirow{2}{*}{$\begin{array}{l}\text { Duration } \\
\text { of delirium } \\
(h r)\end{array}$} & \multirow{2}{*}{$\begin{array}{c}\text { Cases } \\
\text { (no.) }\end{array}$} & \multirow{2}{*}{$\begin{array}{c}\text { Mean } \\
\text { atropine } \\
\text { dose } \\
(m g)\end{array}$} & \multicolumn{2}{|c|}{ Neurological deficit } & \multirow[t]{2}{*}{ Death } \\
\hline & & & $\begin{array}{c}\text { Before } \\
\text { toxicity }\end{array}$ & $\begin{array}{l}\text { After } \\
\text { toxicity }\end{array}$ & \\
\hline $\begin{array}{r}0-12 \\
13-24 \\
25-48 \\
48+\end{array}$ & $\begin{array}{l}10 \\
47 \\
31 \\
12\end{array}$ & $\begin{array}{l}18 \cdot 5 \\
22 \cdot 1 \\
31 \cdot 8 \\
34 \cdot 9\end{array}$ & $\begin{array}{l}0 \\
5 \\
3 \\
1\end{array}$ & $\begin{array}{l}0 \\
2 \\
2 \\
3\end{array}$ & $\begin{array}{l}0 \\
1 \\
0 \\
5^{*}\end{array}$ \\
\hline
\end{tabular}

* Including two with respiratory paralysis.

to show neurological deficits of all types. The paralytic signs were, however, more frequent in late admissions. The total cases in this Table are only 191 as the exact time of ingestion was not known in nine cases.

We tried to correlate individual signs with the serum and RBC levels of cholinesterase enzymes. As we had found before (Karnik et al., 1970), there was no correlation.

ELECTROPHYSIOLOGICAL STUDIES These will be reported later in detail. We wish to record here that in cases with and without paralytic signs we found normal or only mildly slowed nerve conduction. Even in cases with respiratory paralysis nerve conduction velocity measured a few hours before death was greater than $48 \mathrm{~m} / \mathrm{s}$ in median, ulnar, and lateral popliteal nerves. Fibrillations were seen very occasionally in type 2 cases and a poor EMG interference pattern was usual in these cases (12 of 21 cases). There was no evidence of myopathic motor unit potentials.

TABLE 7

CORRELATION OF NEUROLOGICAL SIGNS WITH TIME OF ADMISSION SINCE INGESTION OF POISON

\begin{tabular}{|c|c|c|c|c|c|c|}
\hline \multirow{2}{*}{$\underset{(h r)}{\text { Time }}$} & \multirow{2}{*}{$\begin{array}{l}\text { Cases } \\
\text { (no.) }\end{array}$} & \multirow{2}{*}{$\begin{array}{l}\text { No neuro- } \\
\text { logical } \\
\text { deficit }\end{array}$} & \multicolumn{2}{|c|}{ Unconscious } & \multicolumn{2}{|c|}{ Signs } \\
\hline & & & $\begin{array}{c}\text { With } \\
\text { pulmonary } \\
\text { oedema }\end{array}$ & $\begin{array}{l}\text { Without } \\
\text { marked } \\
\text { oedema }\end{array}$ & Type 1 & Type 2 \\
\hline $\begin{array}{c}0-2 \\
2-4 \\
4-8 \\
8-12 \\
12-24 \\
24+\end{array}$ & $\begin{array}{r}83 \\
51 \\
25 \\
12 \\
14 \\
6\end{array}$ & $\begin{array}{r}65 \\
35 \\
15 \\
3 \\
5 \\
2\end{array}$ & $\begin{array}{l}7 \\
2 \\
1 \\
0 \\
1 \\
-\end{array}$ & $\begin{array}{l}0 \\
5 \\
2 \\
1 \\
0 \\
1\end{array}$ & $\begin{array}{l}4 \\
5 \\
1 \\
3 \\
3 \\
3\end{array}$ & $\begin{array}{l}9 \\
6 \\
7 \\
4 \\
6\end{array}$ \\
\hline
\end{tabular}

Decremental responses were looked for at 3,10, and 30 stimuli per second by standard tests (Cohen and Brumlik, 1968; Smorto and Basmajian, 1972). In 17 such tests in 11 paralysed patients we demonstrated a decremental response in three patients when stimulated at $10 / \mathrm{s}$ and in six of the 11 when tested at 30/s. In five cases we were unable to demonstrate neuromuscular block even in the presence of clinical paralysis. On the other hand, in some cases the neuromuscular block was demonstrated in the absence of any neurological deficit and up to seven days after the poisoning.

We interpret these electrophysiological data as 
evidence of lesions at the myoneural junction and at the anterior horn cells. Histopathological studies with teased nerve preparations also showed axonal degeneration with some segmental demyelination (Wadia et al., to be published).

\section{DISCUSSION}

The incidence of neurological signs recorded herein far exceeds any so far reported in the literature. Unconsciousness and fasciculations are commonly described (Mutalik et al., 1962; Shankar, 1967; Namba et al., 1971). We confess that up to 1969 we had missed these paralytic signs. Two previous publications of ours recorded unconsciousness and fasciculations. In the second (Karnik et al., 1970) we spoke of muscle weakness without delineating any specific signs. This had also been the experience in several Indian papers on Diazinon poisoning (Vishwanathan and Srinivasan, 1964; De and Chatterjee, 1967; Shankar, 1967; Balani et al., 1968; Gupta and Patel, 1968). This is probably because a complete neurological examination was usually omitted when the diagnosis was so obvious. Kabrawalla and Solanki (1971) have reported a single case with 9th and 10th cranial nerve palsies in their series of 43 cases. The western literature also fails to record the gamut of paralytic signs noted here. Namba et al. (1971) report weakness in 47 , difficulty in walking in 22, and speech disturbance in 20 cases. Davignon et al. (1965) examined 441 agricultural workers and recorded weakness in $7.3 \%$ and ataxia in $1.5 \%$. Grob and Harvey (1953) mention central signs like anxiety, restlessness, emotional lability, nightmares, and confused speech. We saw these signs in plenty but are convinced that in our series they were chiefly due to atropine toxicity. The concomitant presence of tachycardia and flushed skin and the regression of these signs when atropine was stopped and their persistence when atropine was continued all point to this.

One explanation of why we noted signs not recorded in the western literature is, of course, the question of treatment. Diazinon is a cholinesterase inhibitor and this results in the accumulation of acetylcholine producing muscarinic, nicotinic, and central signs. Diazinon poisoning is treated with atropine and P2AM. Atropine is the physiological antidote and combats the muscarinic and central effects of acetylcholine but it has no effects on the nicotinic signs. P2AM reactivates cholinesterase (Wilson and Ginsberg, 1955; Namba and Hiraki, 1958) and therefores improves the clinical picture and is especially useful for the nicotinic signs where atropine⿳亠丷厂 alone is ineffective. In India, P2AM is not readily? available because of import restrictions. In these $\overrightarrow{\bar{\omega}}$ 200 cases P2AM was given to nine patients in extremis where it helped little or not at all, probably because it was given too late (Namba and Hiraki, 1958; Wadia et al., 1971). Signs noted on admission are therefore attributed to action of acetylcholine at muscarinic and nicotinic receptors. The signs which clear with atropine are muscarinic. Those that do not clear or $\vec{\omega}$ actually appear while on atropine treatment (type 2 signs) are nicotinic. Nicotinic signs seem to appear later than muscarinic. Thus, if a patient comes early to hospital he has pure. muscarinic signs (type 1a) and if he comes latio oo he has both muscarinic and nicotinic neuros logical signs (type 1b). The neurological defici which occurs later may be purely nicotinic (type 2). The overlap seen in Table 4 is neatly explaine $\mathbb{B}$ by this hypothesis.

There is, however, a second possible explanxa tion for type 2 signs. Organophosphorous insecticides inhibit many esterases and these signs may be due to 'neurotoxicity'. This has nothing to do with acetylcholine and is probably related to other esters inhibited. As such it would not be affected by atropine. This is the mechanism of neurological signs in tri-o'cresyl phosphate (TOCP) poisoning (Aldridge and Johnson, 1971).

There are several points in favour of the first alternative, however: (1) Neurotoxicity, whether it is due to TOCP or is experimentally produced, has a characteristic clinical picture (Davies et al., 1960). There is a delay of more than seven days (usually 10-21 days) followed by ataxia, distal paraesthesiae, and distal weakness and wasting with long lasting paralysis. The picture we noted was very different. (2) The incidence of the paralytic signs is particularly high in this series. Thus Quinby (1964) recorded 24 cases treated with PAM and atropine. Though 11 of these had initial impairment of consciousness, implying a more serious group, no signs akin to our type 2 were noted. The treatment given in our series 
would be expected to allow more nicotinic signs than usual. (3) The organophosphorous insecticides are known to cause accumulation of acetylcholine and to give rise to muscarinic and nicotinic signs. We saw a profusion of muscarinic signs. It would be odd if fasciculations were the sole nicotinic signs, especially as no treatment for these was given. Acetylcholine is known to produce a depolarization neuromuscular block and it seems to us more likely that the transient lower motor neurone type weakness with neuromuscular block seen in these cases was due to a nicotinic effect of acetylcholine than to any other mechanism.

The presence of pathological changes in the nerves in our fatal cases requires explanation. It would be easy to claim that the fatal cases were the ones showing neurotoxicity, and that was the cause of fatality. As mentioned before, the onset and nature of paralytic signs differed in no way between survivors and fatal cases and it does not appear satisfactory to give two separate mechanisms for these two sets of cases. Thus our pathological data confirm that we have observed 'neurotoxicity' with Diazinon (and this has not been recorded with this agent before to our knowledge) but our clinical data appear to point to a different variety than that usually understood by that term. The picture we have is reminiscent of the results found by Gaines (1969) in experiments on chicks. Gaines also gave only atropine as protection against toxicity. $\mathrm{He}$ had no pathological data. We confess, however, that we have no final proof of the mechanism of these signs and our postulate requires further experimental study. PAM may have protective action by some other mechanism.

Finally, we wondered why paralysis was seen in only some cases and why some patients showed neuromuscular block, and others did not. The organophosphorous insecticides are a class of compounds where the action is known up to the enzyme level and obviously a study of pharmacogenetic variation is warranted. We are studying this problem further.

\section{REFERENCES}

Aldridge, W. N., and Johnson, M. K. (1971). Side effects of organophosphorus compounds: delayed neurotoxicity. Bulletin of the World Health Organization, 44, 259-263.
Balani, S. G., Fernandes, S. O., Lakhani, R. H., and Duthani, V. J. (1968). Diazinon poisoning. Journal of the Association of Physicians of India, 16, 911-917.

Cohen, H. L., and Brumlik, J. (1968). A Manual of Electroneuromyography. Hoeber: New York.

Davies, D. R., Holland, P., and Rumens, H. J. (1960). The relationship between the chemical structure and neurotoxicity of alkyl organophosphorus compounds. British Journal of Pharmacology, 15, 271-278.

Davignon, L. F., St-Pierre, J., Charest, G., and Tourangeau, F. J. (1965). A study of the chronic effects of insecticides in man. Canadian Medical Association Journal, 92, 597-602.

De, S. C., and Chatterjee, S. C. (1967). Poisoning with organic phosphorous insecticides. Journal of the Indian Medical Association, 48, 153-157.

Gaines, T. B. (1969). Acute toxicity of pesticides. Toxicology and Applied Pharmacology, 14, 515-534.

Grob, D., and Harvey, A. M. (1953). Effects and treatment of nerve gas poisoning. American Journal of Medicine, 14, 52-63.

Gupta, O. P., and Patel, D. D. (1968). Diazinon poisoning. A study of sixty cases. Journal of the Association of Physicians of India, 16, 457-463.

Holmstedt, B. (1959). Pharmacology of organophosphorus cholinesterase inhibitors. Pharmacological Review's, 11, 567-688.

Kabrawala, V. N., and Solanki, S. V. (1971). Pralidoxime chloride as an adjunct in treatment of diazinon poisoning. Journal of the Association of Physicians of India, 19, 273277.

Karnik, V. M., Ichaporia, R. N., and Wadia, R. S. (1970). Cholinesterase levels in diazinon poisoning. 1. Relation to severity of poisoning. Journal of the Association of Physicians of India, 18, 337-344.

Mutalik, G. S., Wadia, R. S., and Pai, V. R. (1962). Poisoning by diazinon, an organophosphorous insecticide. Journal of the Indian Medical Association, 38, 67-71.

Nachmansohn, D., and Feld, E. A. (1947). Studies on cholinesterase. 4. On the mechanism of diisopropyl fluorophosphate action in vivo. Journal of Biological Chemistry, 171, 715-724.

Namba, T., and Hiraki, K. (1958). PAM (pyridine 2aldoxime methiodide) therapy for alkylphosphate poisoning. Journal of the American Medical Association, 166, 1834-1839.

Namba, T., Nolte, C. T., Jackrel, J., and Grob, D. (1971). Poisoning due to organophosphate insecticides. Acute and chronic manifestations. American Journal of Medicine, 50, 475-492.

Quinby, G. E. (1964). Further therapeutic experience with pralidoximes in organic phosphorus poisoning. Journal of the American Medical Association, 187, 202-206.

Shankar, P. S. (1967). Pulmonary oedema in diazinon poisoning. Indian Journal of Chest Diseases, 9, 106-110.

Smorto, M. P., and Basmajian, J. V. (1972). Clinical Electroneurography. Williams and Wilkins: Baltimore.

Vishwanathan, M., and Srinivasan, K. (1964). Treatment of organo-phosphorous compound poisoning. Journal of the Indian Medical Association, 43, 494-495.

Wadia, R. S., Karnik, V. M., and Ichaporia, R. N. (1971). Cholinesterase levels in diazinon poisoning. A study of the effect of PAM in treatment. Journal of the Association of Physicians of India, 19, 185-191.

Wadia, R. S., and Pherwani, R. G. (1969). Unpublished observations.

Wilson, I. B., and Ginsburg, S. (1955). A powerful reactivator of alkylphosphate-inhibited cholinesterase. Biochimica et Biophysica Acta, 18, 168-170. 